\title{
Fuzzy-based power exchange management between grid-tied interconnected residential microgrids
}

\author{
Diego Arcos-Aviles \\ Department of Electrical \\ and Electronics \\ Engineering \\ Universidad de las Fuerzas \\ Armadas ESPE \\ Sangolquí, Ecuador \\ dgarcos@espe.edu.ec
}

\author{
Alexander Ibarra \\ Department of Electrical, \\ Electronics and \\ Telecommunications \\ Engineering \\ Universidad de las Fuerzas \\ Armadas ESPE \\ Sangolquí, Ecuador \\ oaibarra@espe.edu.ec
}

\author{
Gabriel García-Gutierrez \\ Department of Electrical \\ and Electronics \\ Engineering \\ Universidad de las Fuerzas \\ Armadas ESPE \\ Sangolquí, Ecuador \\ gmgarcia3@espe.edu.ec
}

\author{
Emilia Motoasca \\ Department of Electrical \\ Engineering \\ Faculty of Engineering \\ Technology-TC Ghent \\ KU Leuven \\ Ghent, Belgium \\ emilia.motoasca@kuleuven.be
}

\author{
Francesc Guinjoan \\ Department of Electronics \\ Engineering \\ Universitat Politècnica de \\ Catalunya - Barcelona \\ TECH \\ Barcelona, Spain \\ francesc.guinjoan@upc.edu
}

Jacqueline Llanos
Department of Electrical
and Electronics
Engineering
Universidad de las Fuerzas
Armadas ESPE
Sangolquí, Ecuador
jdllanos1@espe.edu.ec

\author{
Paúl Ayala \\ Department of Electrical \\ and Electronics \\ Engineering \\ Universidad de las Fuerzas \\ Armadas ESPE \\ Sangolquí, Ecuador \\ jpayala@espe.edu.ec \\ Julio Pascual \\ Department of Electrical \\ Electronic and \\ Communications \\ Engineering \\ Public University of \\ Navarre (UPNa) \\ Pamplona, Spain \\ juliomaria.pascual@unavarra.es
}

\begin{abstract}
This paper presents a fuzzy-based power exchange management between two neighboring residential grid-connected microgrids comprising both photovoltaic generation and battery energy storage system (BESS). The proposed power exchange management accounts for the magnitude of the energy rate-of-change of each microgrid and the charge difference between the BESSs of both microgrids to charge the ESS that has an energy deficit. As such, the proposed power exchange management can reduce the amount of power absorbed from the mains of each microgrid by operating jointly with each other rather than separately, and it also synchronizes the ESS of both microgrids, improving the behavior of ESSs. A comparison of the simulated results for a scenario with and without power exchange is presented in order to demonstrate the adequate behavior of the proposed power exchange management.
\end{abstract}

Keywords-energy management, cooperative microgrid, Fuzzy Logic control, power exchange, grid-tied microgrids

\section{INTRODUCTION}

The growth of energy demand in the last decades has led to the inclusion of alternative generation systems to support the main network, which in turn, has led to the appearance of residential microgrids commonly based on photovoltaic generation and energy storage systems (ESS) [1]. In this residential microgrid scenario, energy management systems (EMS) [2], [3] are responsible for, among others, regulating the power flow within the microgrid to minimize the amount of power absorbed from the main grid while maintaining the comfort of home inhabitants [4].

In residential microgrids $(\mathrm{MG})$, the generation and storage of energy is mostly limited to each MG, therefore by a larger grid of these grid-tied interconnected microgrids is referred as multi-microgrids (MMS) [5] or networked microgrids NMGs. The microgrids involved in an MMS may collaborate with each other on a centralized or decentralized manner in order to allocate resources and coordinate the operation of individual MGs, [6]. Operators of MMS are still confronted with many challenges due to very different owners of MGs, privacy issues and adopted management strategy, actually one among these four strategies for MG management: centralized, decentralized, hybrid, and nested [7]. Not only is the chosen type of EMS important when dealing with MMS but also the strategies for coping with contingencies. Some of these strategies presented in various publications, like e.g., [5], [8], [9], include solving of unforeseen events by using variable weighted multi-objective functions, where the weights are changed depending of the type of contingency and based on an efficient optimization algorithm called targeted search shuffled complex evolution for quick decisions. However, this seems a time-consuming strategy since all possible types of contingencies should be accounted for in development of the algorithms. Many of the published literature related to MMS makes use of Model predictive control (MPC) strategies for developing EMS in such MMS, like [8], [10], [11] that describe hierarchical stochastic energy management strategies for MMS with endogenous and exogenous sources of uncertainties. However, as many authors have shown the MPC strategies have the drawback of longer computational times depending on various parameters. Bi-level EMS wherein both exchange of information and power is possible are also common in the literature [6], [12], [13]. Most of these models, mostly multiagent-based models, analytical models and auction models, include also energy pricing and (peer-to-peer, P2P) trading components among the participants and various cooperation and decision making strategies, like in [14]-[20]. In the very comprehensive overview in [21] the limitations of EMS for resilient interconnected MGs have been studied to show that there may exist fundamental discrepancies between real and estimated system states of an EMS due to the uncertainties in the real systems.

Since one of the critical components in MGs, with large impact on MG's total costs, is the battery ESS (BESS), care is needed when designing EMS to guarantee the optimal use of these BESSs. It is known that the lifetime of the battery reduces during charging and discharging cycles, therefore state-of-charge (SOC) of the BESS should remain in the safe and advisable ranges. Cooperation strategies for energy

(C) 2020 IEEE. Personal use of this material is permitted. Permission from IEEE must be obtained for all other uses, in any current or future media, including reprinting/republishing this material for advertising or promotional purposes, creating new collective works, for resale or redistribution to servers or lists, or reuse of any copyrighted component of this work in other work. 
exchange among individual MGs in an MMS should account for this too, as shown in [22].

Therefore, a power exchange management between two residential grid-connected microgrids is proposed. The EMS proposal is based on fuzzy logic control (FLC), which is oriented to simultaneously minimize the amount of power injected from the main grid to each microgrid and to improve the SOC behavior of the BESS of each microgrid to maximize its lifetime.

This paper is organized as follows. Section II presents the structure and operation of the residential microgrid scenario under analysis. Section III presents the design of the proposed fuzzy-based power exchange management between microgrids. Section IV presents the simulation and comparison results. Finally, Section V presents the main conclusions of this work.

\section{MiCROGRID STRUCTURE AND OPERATION}

\section{A. Microgrid architecture}

0 shows the cooperative power system scheme composed of two grid-tied interconnected residential microgrids. Each microgrid comprises a photovoltaic (PV) generator, a BESS based on lead-acid batteries and an aggregated load representing the total residential energy consumption. The BESS and the utility grid are responsible for performing the power balance between consumption and generation. Each microgrid has its own microgrid-EMS, which is responsible for the management of the different distributed energy resources (DER) to smooth the grid power profile in each grid-connected microgrid [23]. Both microgrids are linked together to allow the power exchange between them.

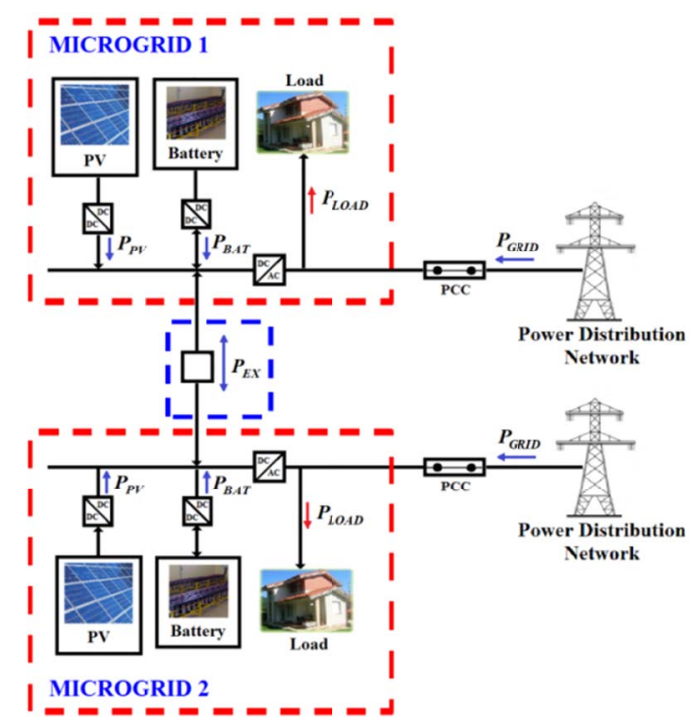

Fig. 1. Scheme of two grid-tied interconnected residential microgrids

For each of the microgrids in $0, P_{P V}$ is the PV power, $P_{L O A D}$ is the load power, $P_{B A T}$ is the battery power, $P_{G R I D}$ is the power that each microgrid exchanges with the power distribution network and $P_{E X}$ is the power exchanged between the microgrids. It is worth noting that a positive battery power (i.e., $P_{B A T}>0$ ) denotes a discharging process of the BESS, whereas a negative one (i.e., $P_{B A T}<0$ ) implies a charging process). Similarly, a positive $P_{G R I D}$ indicates a power deficit in the microgrid, whereas a negative $P_{G R I D}$ means a surplus of generated power in the microgrid.

\section{B. Operation of the grid-connected microgrids}

As aforementioned, each microgrid operates according to the EMS described in [23] aiming at smoothing the grid power profile exchanged with the mains while minimizing the grid power peaks and rapid fluctuations. This EMS uses the microgrid energy rate-of-change (ERoC) to quantify the magnitude of the energy changes produced within the microgrid and predict, in this way, the battery SOC's future behavior if the grid power profile is invariant.

In such a context, the EMS computes the grid power profile, of each microgrid, using from to , as follows:

$$
\begin{gathered}
P_{G R I D}(n)=P_{A V G}(n)+P_{F L C}(n) \\
P_{A V G}(n)=\frac{1}{M} \sum_{k=n-M}^{n-1} P_{L G}(k) \\
P_{L G}(n)=P_{L O A D}(n)-P_{P V}(n)
\end{gathered}
$$

where $n$ is the current sample, $M$ is the number of samples per day, $P_{L G}$ is the MG power balance, $P_{A V G}$ is the average value of the MG power balance, and $P_{F L C}$ is the output of an FLC block, which is in charge of smoothing the grid power profile while keeping the BESS's operation between secure limits to preserve the battery lifetime.

On one hand, the constraints of the BESS, namely the maximum and minimum SOC values, $S O C_{M A X}$ and $S O C_{M I N}$, respectively, are defined as follows, when accounting for the depth of discharge (DOD) of lead-acid battery bank:

$$
\begin{aligned}
& S O C_{M I N} \leq S O C(n) \leq S O C_{M A X} \\
& S O C_{M I N}=(1-D O D) \cdot S O C_{M A X}
\end{aligned}
$$

On the other hand, the battery power $P_{B A T}$, is related to the SOC of the BESS. The EMIS described in [23] defines the battery power and the estimation of the current battery SOC, as follows:

$$
\Delta \operatorname{SOC}(n)=\frac{100}{C_{B A T}} \cdot \eta \cdot P_{B A T}(n-1) \cdot T_{s}
$$

where $C_{B A T}$ is the battery rated capacity and $\eta$ is the battery efficiency (i.e., charge $\eta=\eta_{C}$ and discharge $\eta=1 / \eta_{D}$ ) and $T_{s}$ is the sampling period [23]-[251].

Each microgrid operates following the block diagram depicted in Fig. 2, which is based on the microgrid ERoC, $\dot{P}_{A V G}(n)$ defined in (7), and the SOC of the BESS. It is worth noting that $\dot{P}_{A V G}(n)$ is understiood as the local prediction of the battery SOC future behavior if the grid power is not modified [23]. Please refer to [23] for a complete description of each block depicted in Fig. 2.

$$
\dot{P}_{A V G}(n)=\left[P_{A V G}(n)-P_{A V G}(n-1)\right] / T_{S}
$$

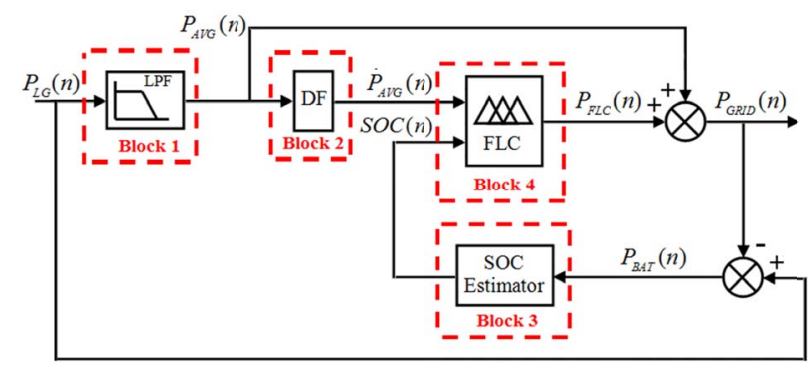

Fig. 2. Block diagram of the fuzzy-based EMS based on microgrid energy rate-6-change [23] 


\section{FuZzY-BASEd Power EXChange Management}

\section{A. Control policy}

The power exchange management is developed following the next control policy:

1) The power exchange between microgrids is performed as such to minimize the amount of power that each microgrid individually absorbs from the main network.

2) The energy stored in the BESS of MG1 is used to charge the BESS of MG2 (i.e., power exchange from MG1 to MG2) if the battery's SOC of MG1 is higher than the battery's SOC of MG2; it means that MG1 has a negative ERoC (i.e., increase of power generation or decrease in power consumption), and MG2 has a positive ERoC (i.e., increase of load consumption or decrease in generating power).

3) The energy stored in the BESS of MG2 is used to charge the BESS of MG1 (i.e., power exchange from MG2 to MG1) if the battery's SOC of MG1 is lower than the battery's SOC of MG2, thus MG1 has a positive ERoC, and MG2 has a negative ERoC.

4) The power exchange between microgrids is proportional to the available battery SOC level and the magnitude of ERoC when both microgrids have a positive or a negative ERoC at the same time.

Following this control policy, the batteries SOC of both microgrids will tend to synchronize, leading further to a decrease in the amount of power that one microgrid absorbs from the mains, since the required power comes partly from the other microgrid and not all from the mains. In addition, deep cycles of discharge in the BESSs are avoided. This behavior induces further a decrease in the amount of power that one microgrid injects into the utility grid since its surplus power is injected into the other microgrid, consequently, avoiding overcharges in the BESS.

\section{B. Fuzzy-based power exchange management}

For purposes of the energy exchange, the computation of the power injected into each BESS is redefined and includes a new component corresponding to the energy that will be extracted or injected depending on the energy exchange scenario. In a no-exchange scenario (see Fig. 2), the power injected into each ESS, is according to [23], where $M G_{x}$ is either MG1 or MG2:

$$
P_{B A T(M G x)}(n)=P_{L G(M G x)}(n)-P_{G R I D(M G x)}(n)
$$

Now the expressions are redefined to implement the energy exchange as follows:

$$
\begin{aligned}
& P_{B A T(M G 1)_{X C}}(n)= P_{B A T(M G 1)}(n)-P_{X C_{1-2}} \cdot P_{B A T(M G 1)}^{s}(n) \cdots \\
& \cdots+P_{X C_{2-1}} \cdot P_{B A T(M G 2)}^{s}(n) \\
& P_{B A T(M G 2)_{X C}}(n)= P_{B A T(M G 2)}(n)-P_{X C_{2-1}} \cdot P_{B A T(M G 2)}^{s}(n) \cdots \\
& \cdots+P_{X C_{1-2}} \cdot P_{B A T(M G 1)}^{s}(n) \\
& P_{B A T(M G x)}^{s}(n)=\left(1 / T_{s}\right) \cdot E_{B A T(M G x)}(n)
\end{aligned}
$$

where $P_{X C 1-2}$ and $P_{X C 2-1}$ are the outputs of the FLC that manages the energy exchange according to the value of its inputs and to the defined linguistic rules and $P_{B A T(M G x)}^{s}$ is the available power in the BESS according to the available stored energy $E_{B A T(M G x)}$. A complete scheme of the power exchange management is presented in Fig. 3.

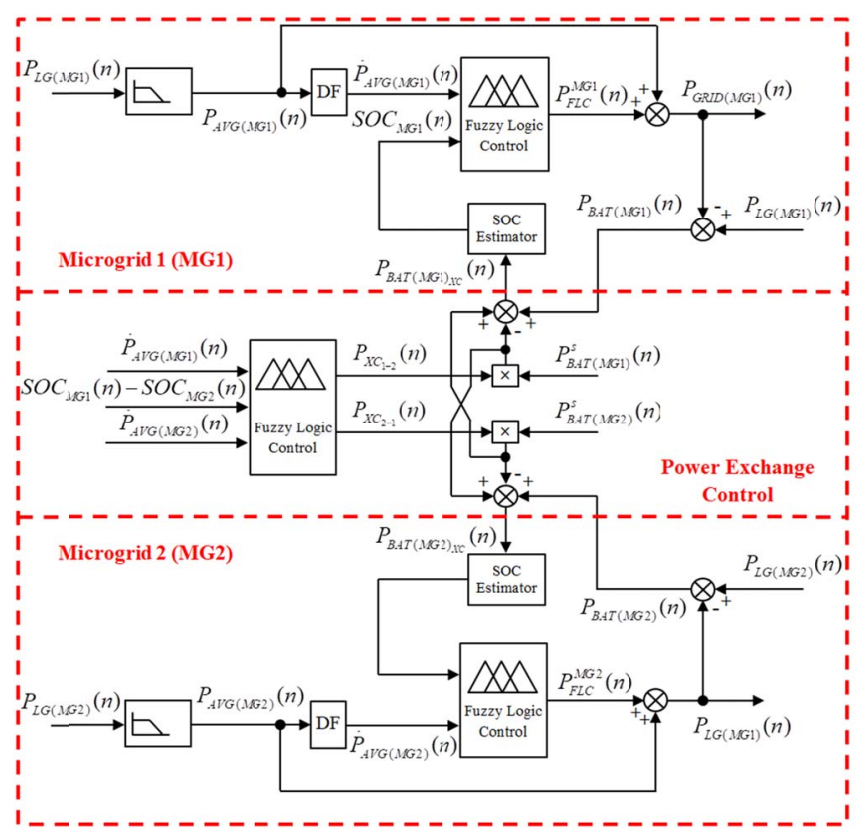

Fig. 3. Block diagram of the proposed power exchange management

As shown in Fig. 3, the inputs of the FLC are $\dot{P}_{A V G(M G 1)}(n)$ and $\dot{P}_{A V G(M G 2)}(n)$ the ERoC of both MGs, to establish the trend, i.e., the futture behavior without using a forecasting approach, of each $\mathrm{MG}$, trend that can be negative (i.e., increase of power generation) or positive (i.e., increase of load consumption); and $S_{O C C_{M G I}}(n)-S O C_{M G 2}(n)$ the difference between the battery's SOC of MG1 and MG2, to determine which BESS has more energy stored. The outputs of the FLC are $P_{X C l-2}$ and $P_{X C 2-1}$ the percentages of energy that will be exchanged from MG1 to MG2 and from MG2 to MG1, respectively, according to the control policy described in Section III.A.

The FLC block assumes a Mamdani based inference and defuzzification of Center of Gravity. The input variables $\dot{P}_{A V G(M G I)}(n)$ and $\dot{P}_{A V G(M G 2)}(n)$ are mapped into fuzzy sets represented by four membership functions (MF), namely negative big (NB), negative small (NS), positive small (PS), and positive big (PB), as shown in Fig. 4. The input variable $S_{M G 1}(n)-S_{M O C_{M G}}(n)$ is mapped into fuzzy sets represented by two trapezoidal MFs, namely negative (N) and positive (P), as shown in Fig. 5.

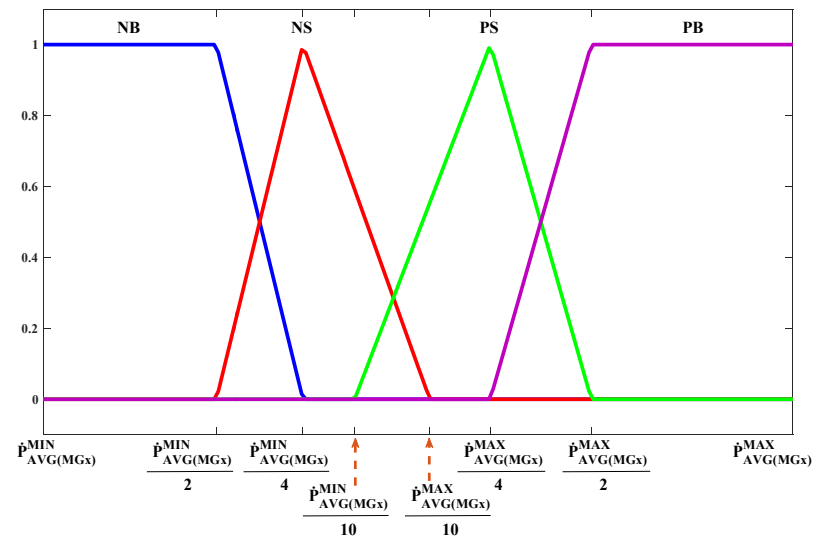

Fig. 4. Membership functions (MF) of input energy rate-of-change (ERoC) of microgrid 1 (MG1) $\dot{P}_{A W G(M G 2)}$ and of microgrid 2 (MG2) $\dot{P}_{A V G(M G 2)}$ 


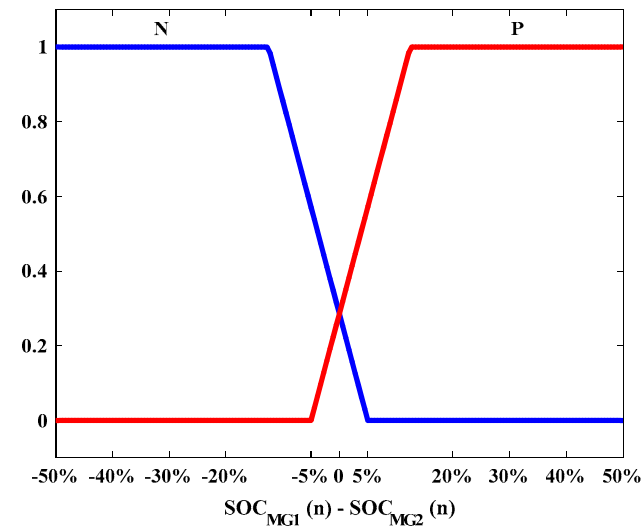

Fig. 5. MFs of the difference in charge between the energy storage systems of MG1 and MG2

Similarly, the output variables $P_{X C 1-2}(n)$ and $P_{X C 2-1}(n)$ are mapped into four fuzzy sets represented by four triangular MFs, namely zero (ZE), small (S), medium (M), and big (B), as shown in Fig. 6(a) and Fig. 6(b).

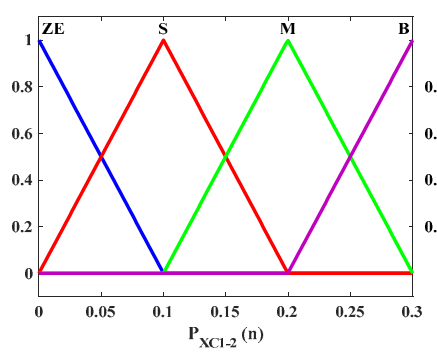

(a)

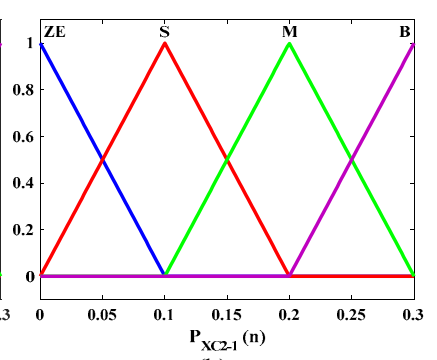

(b)
Fig. 6. MFs of the fuzzy logic outputs (a) $P_{X C 1-2}(n)$ and (b) $P_{X C 1-2}(n)$

The inputs and outputs MFs are distributed along the variation range defined as:

$$
\begin{gathered}
\dot{P}_{A V G(M G x)}^{M I N} \leq \dot{P}_{A V G(M G x)}(n) \leq \dot{P}_{A V G(M G x)}^{M A X} \\
-50 \% \leq S O C_{M G 1}(n)-S O C_{M G 2}(n) \leq 50 \% \\
0 \leq P_{X C_{1-2}}(n) \leq 0.3 \quad 0 \leq P_{X C_{2-1}}(n) \leq 0.3
\end{gathered}
$$

where $\dot{P}_{A V G(M G x)}^{M I N}$ and $\dot{P}_{A V G(M G x)}^{M A X}$ are the minimum and maximum variation of ERoC (i.e., derivative term computed by block 2 of Fig. 2), respectively, of each microgrid MG1 and MG2, which according to [23] are expressed in W/s and are calculated using the approximation developed in [26] considering a time window $T_{W}$, of one day (i.e., $T_{W}=60 \cdot 60 \cdot 24=86400 \mathrm{~s}$ ). Note that this study assumes a scenario where two neighboring residential microgrids exchange energy. In this scenario, it is considered that the two residences have a different consumption profile and since they are neighbors, the generation of photovoltaic power is the same. Therefore:

$$
\begin{gathered}
\dot{P}_{A V G(M G x)}^{M A X}=(9 / 10) \cdot\left(P_{L O A D(M G x)} / T_{W}\right) \\
\dot{P}_{A V G(M G x)}^{M I N}=(9 / 10) \cdot\left(P_{P V} / T_{W}\right)
\end{gathered}
$$

where $P_{L O A D(M G x)}$ is the load power of MG1 or MG2, respectively.

Under different operating conditions, the control policy can be described in terms of 32 linguistic rules implemented in the FLC. For instance, the heuristic knowledge, for the highlighted rule, is explained next:
IF the BESS of MG1 has a higher amount of energy stored than the BESS of MG2 (i.e., $S O C_{M G 1}-S O C_{M G 2}$ is P) AND the MG1 has a strong negative ERoC, which implies a strong increase of power generation or a strong decrease in power consumption (i.e., $\dot{P}_{A V G(M G I)}$ is NB) AND the MG2 has a strong positive ERoC, which implies a strong increase of load consumption or a strong decrease in generating power (i.e., $\dot{P}_{A V G(M G 2)}$ is PB) THEN a large percentage of the energy

\begin{tabular}{|c|c|c|c|c|c|}
\hline \multirow{2}{*}{\multicolumn{2}{|c|}{$\boldsymbol{P}_{X C 1-2}(\boldsymbol{n}){ }_{P_{X C 2-1}(n)}$}} & \multicolumn{4}{|c|}{$\dot{P}_{A V G(M G 2)}(n)$} \\
\hline & & \multirow{2}{*}{$\frac{\text { NB }}{S / Z E}$} & \multirow{2}{*}{$\frac{\text { NS }}{\mathrm{M} / \mathrm{ZE}}$} & \multirow{2}{*}{$\frac{\text { PS }}{\mathrm{B} / \mathrm{ZE}}$} & \multirow{2}{*}{$\frac{\text { PB }}{\mathrm{B} / \mathrm{ZE}}$} \\
\hline \multirow{4}{*}{$\dot{P}_{A V G(M G I)}(n)$} & NB & & & & \\
\hline & NS & S/ZE & $\mathrm{M} / \mathrm{ZE}$ & $\mathrm{M} / \mathrm{ZE}$ & $\mathrm{B} / \mathrm{ZE}$ \\
\hline & PS & ZE/ZE & ZE/ZE & $\mathrm{M} / \mathrm{ZE}$ & $\mathrm{M} / \mathrm{ZE}$ \\
\hline & PB & S/ZE & $\mathrm{S} / \mathrm{ZE}$ & ZE/ZE & S/ZE \\
\hline \multicolumn{2}{|c|}{$S O C_{M G 1}(n)-S O C_{M G 2}(n)$} & \multicolumn{4}{|c|}{$\mathbf{P}$} \\
\hline \multirow[t]{2}{*}{$\boldsymbol{P}_{X C l-2}(n)$} & \multirow{2}{*}{$P_{X C 2-1}(n)$} & \multicolumn{4}{|c|}{$\dot{P}_{A V G(M G 2)}(n)$} \\
\hline & & NB & NS & PS & PB \\
\hline \multirow{4}{*}{$\dot{P}_{A V G(M G I)}(n)$} & NB & $\mathrm{ZE} / \mathrm{S}$ & ZE/S & ZE/ZE & $\mathrm{ZE} / \mathrm{S}$ \\
\hline & NS & ZE/M & ZE/M & ZE/ZE & $\mathrm{ZE} / \mathrm{ZE}$ \\
\hline & PS & ZE/B & ZE/M & ZE/M & ZE/S \\
\hline & PB & ZE/B & ZE/M & $\mathrm{ZE} / \mathrm{S}$ & $\mathrm{ZE} / \mathrm{S}$ \\
\hline \multicolumn{2}{|c|}{$S O C_{M G 1}(n)-S O C_{M G 2}(n)$} & \multicolumn{4}{|c|}{$\mathbf{N}$} \\
\hline
\end{tabular}
stored in the BESS of MG1 is exchanged to the BESS of MG2 (i.e., $P_{X C l-2}$ is B and $P_{X C 2-1}$ is $\mathrm{ZE}$ ). Consequently, there is a power exchange from MG1 to MG2 only.

TABLE I. POWER EXCHANGE FUZZY LOGIC RULE-BASE

The adjustment of all parameters involved in the fuzzy controller (e.g., number of MFs per input/output, mapping, and rule-base), is performed by an off-line adjustment procedure [27] towards minimization of a set of quality criteria. This set of quality criteria are defined in [23]-[25], [28], [29] and includes $P_{G, M A X}$ the maximum power delivered by the grid in one year, $P_{G, M I N}$ the maximum power fed into the grid in one year, $M P D$ the maximum power derivative of $P_{G R I D}$ in one year, $A P D$ the yearly average power derivative of $P_{G R I D}, P V R$ the power variation range of $P_{G R I D}$, and $P P V$ the grid power profile variability. These criteria are used to quantify the performance of an EMS, where a lower value implies an improved EMS.

\section{SimUlation RESUltS}

The performance of the proposed EMS is tested using the same generation profile in both microgrids and different consumption profile in each microgrid. Fig. 7 presents the grid power profile of MG1 before and after performing the power exchange (PE) with MG2. It can be seen that the grid power profile of MG1 has reduced its power peaks (area marked with red dashed circles on top graph) after the power exchange and the maximum power absorbed from the mains is $P_{G, M A X}=1.910 \mathrm{~kW}$ while the maximum power injected to the mains is $P_{G, M I N}=-1.483 \mathrm{~kW}$. Furthermore, Fig. 8 shows the evolution of battery SOC for MG1. It can be seen that BESS of MG1 is more efficiently managed and prevents the battery SOC from approaching its full charge and minimum discharge limit. This behavior is best presented in Fig. 9 where the operation of the proposed fuzzy-based power exchange management on six consecutive days is shown. 


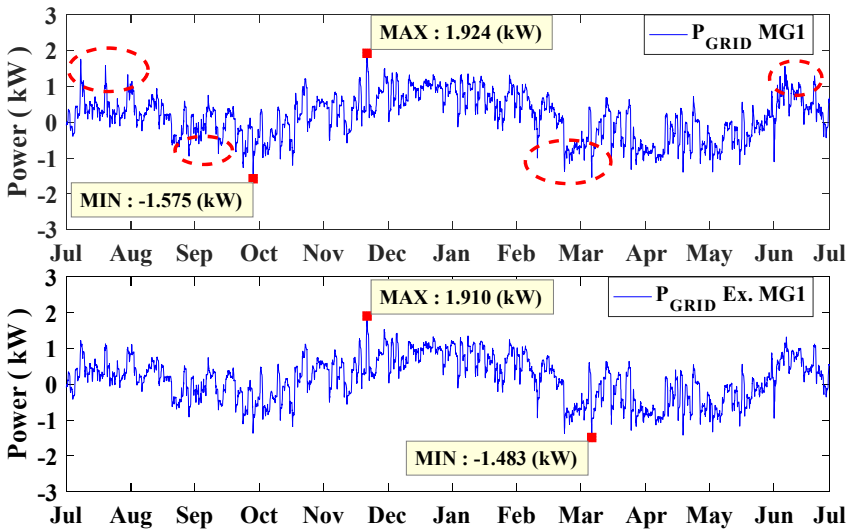

Fig. 7. Yearly grid power profile of MG1 before (top) and after (bottom) the power exchange with MG2

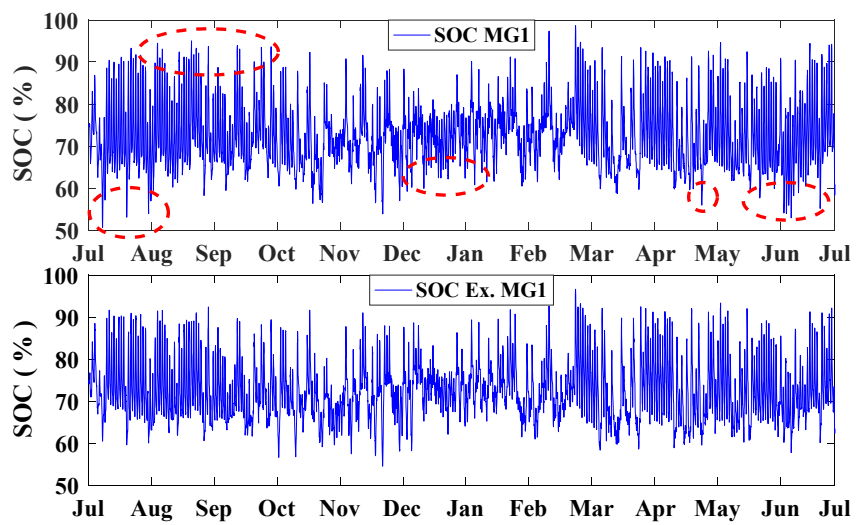

Fig. 8. Yearly evolution of battery SOC of MG1 before (top) and after (bottom) the power exchange with MG2

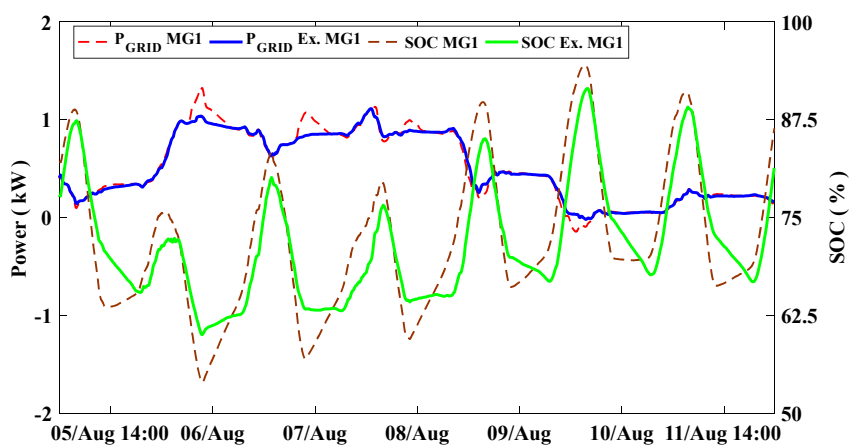

Fig. 9. Grid power profile and battery SOC of MG1 before and after using the proposed fuzzy-based power exchange management on 6 consecutive days

Similarly, Fig. 10, Fig. 11, and Fig. 12 show that the same results are achieved in MG2, namely reduction of power peaks and improved BESS management, for instance as shown in Fig. 10, the maximum power absorbed from the mains is $P_{G, M A X}=1.535 \mathrm{~kW}$ and the maximum power fed into the grid is $P_{G, M I N}=-1.515 \mathrm{~kW}$ after performing the power exchange between microgrids.

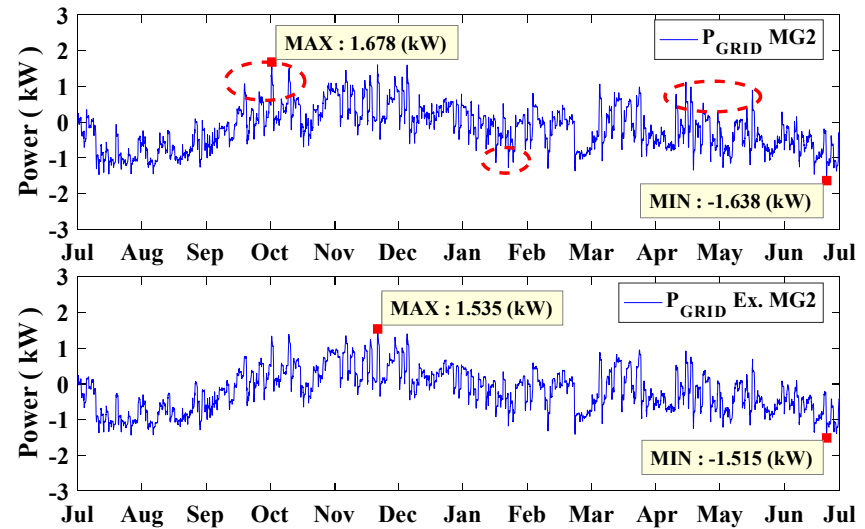

Fig. 10. Yearly grid power profile of MG2 before (top) and after (bottom) the power exchange with MG1

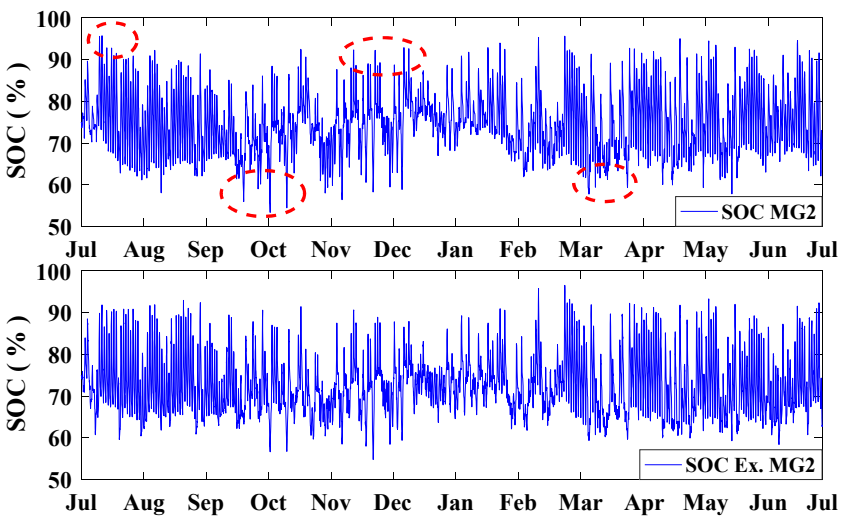

Fig. 11. Yearly battery SOC of MG2 before (top) and after (bottom) the power exchange with MG1

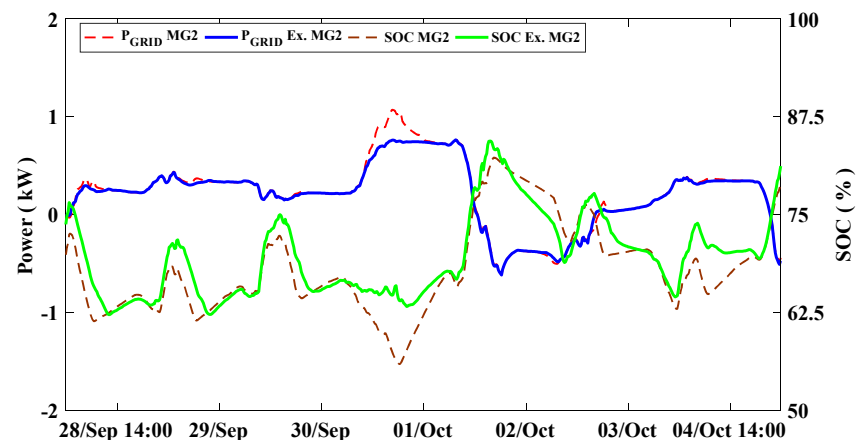

Fig. 12. Grid power profile and battery SOC of MG2 before and after using the proposed fuzzy-based power exchange management on 6 consecutive days

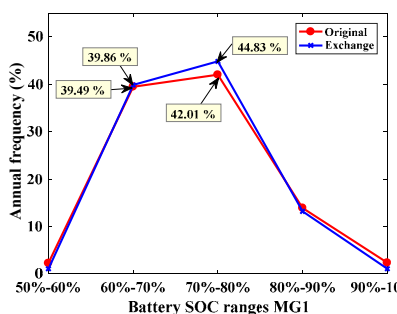

(a)

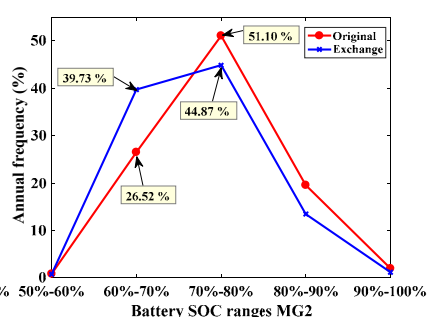

(b)
Fig. 13. Histogram (in \%) of the battery SOC ranges established for MG1 and MG2 before and after using the proposed fuzzy-based power exchange management

Fig. 14 presents the behavior of ESSs of both MG1 and MG2 during two periods of six consecutive days. It can be observed that before performing the power exchange between microgrids, each BESS operates autonomously 
intending to improve the individual performance of each microgrid. However, after performing the power exchange, both BESSs are synchronized, improving the behavior of each microgrid for working together rather than individually.
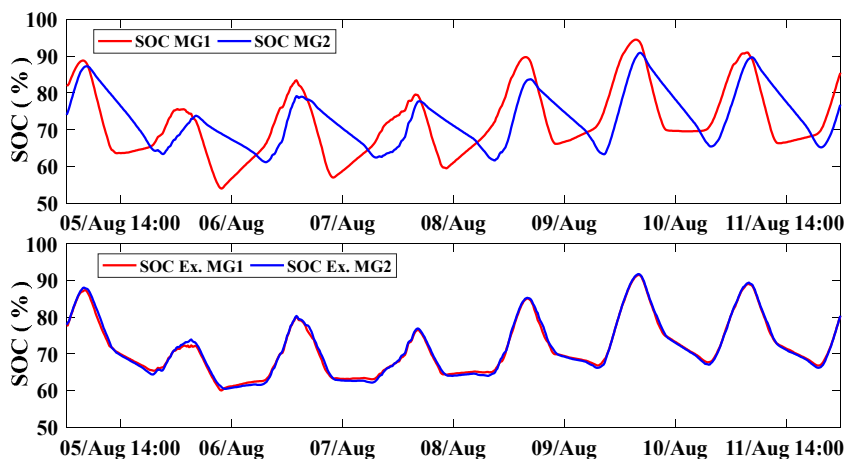

Fig. 14. The battery SOC of MG1 and MG2 before and after the power exchange between them.

Finally, the proposed fuzzy-based power exchange management achieves an important reduction in the magnitude of the defined quality criteria concerning the individual performance of each microgrid without power exchange. In short, after the power exchange between microgrids, the absolute values of all defined quality criteria has been reduced, which results are summarized in Table II.

TABLE II. QUALITY CRITERIA COMPARISON BEFORE AND AFTER THE POWER EXCHANGE BETWEEN MICROGRIDS

\begin{tabular}{|c|c|c|c|c|c|c|}
\hline \hline \multirow{2}{*}{ Scenario } & \multicolumn{6}{|c|}{ Grid power profile quality criteria } \\
\cline { 2 - 7 } & $\begin{array}{c}\boldsymbol{P}_{G, M A X} \\
(\mathbf{k W})\end{array}$ & $\begin{array}{c}\boldsymbol{P}_{G, M I N} \\
(\mathbf{k W})\end{array}$ & $\begin{array}{c}\text { MPD } \\
(\mathbf{W} / \mathbf{h})\end{array}$ & $\begin{array}{c}\boldsymbol{A P D} \\
(\mathbf{W} / \mathbf{h})\end{array}$ & $\boldsymbol{P V R}$ & $\boldsymbol{P P V}$ \\
\hline $\begin{array}{c}\text { MG1 before } \\
\text { PE }\end{array}$ & 1.924 & -1.575 & 661 & 41.84 & 0.34 & 2.51 \\
\hline $\begin{array}{c}\text { MG1 after } \\
\text { PE }\end{array}$ & $\mathbf{1 . 9 1 0}$ & $\mathbf{- 1 . 4 8 3}$ & $\mathbf{6 0 0}$ & $\mathbf{3 8 . 2 9}$ & $\mathbf{0 . 3 3}$ & $\mathbf{2 . 4 6}$ \\
\hline $\begin{array}{c}\text { MG2 before } \\
\text { PE }\end{array}$ & 1.678 & -1.638 & 748 & 42.98 & 0.38 & 2.12 \\
\hline $\begin{array}{c}\text { MG2 after } \\
\text { PE }\end{array}$ & $\mathbf{1 . 5 3 5}$ & $\mathbf{- 1 . 5 1 5}$ & $\mathbf{6 8 5}$ & $\mathbf{3 6 . 6 3}$ & $\mathbf{0 . 3 5}$ & $\mathbf{2 . 0 3}$ \\
\hline \hline
\end{tabular}

\section{CONCLUSIONS}

This paper has presented a fuzzy-based power exchange management between two grid-connected interconnected residential microgrids with renewable generation and battery storage system. The proposed power exchange management has been designed considering the magnitude of the energy rate-of-change of each microgrid and the SOC difference between the BESSs of both microgrids. The proposed strategy has reduced power fluctuations in the grid power profile of both microgrids achieving a maximum power fed into the grid of $1.483 \mathrm{~kW}$ and $1.515 \mathrm{~kW}$ for MG1 and MG2, respectively, and a maximum power injected by the grid of $1.910 \mathrm{~kW}$ and $1.535 \mathrm{~kW}$ for each microgrid. Also, the use of the proposed fuzzy-based power exchange management has improved the battery SOC evolution in the year under study where the battery SOC of each microgrid has kept in a range between $60 \%$ and $80 \%$ of the rated battery capacity the $84 \%$ of the year. The operation of the microgrids under this scheme has led to the BESS of both microgrids being synchronized, which allows improving the behavior of the BESS of each microgrid by working together rather than individually. Finally, the proposed EMS has contributed to the reduction of the quality criteria, which implies an improved quality in the grid power profile. Future work will focus on extending the proposed study for a scenario of multiple interconnected residential microgrids. The behavior of the EMS will be studied when including generation and demand forecast. Besides, interconnection scenarios of multiple isolated microgrids will be analyzed.

\section{ACKNOWLEDGMENT}

This work is part of the projects 2019-PIC-003-CTE and 2020-EXT-007 from the Research Group of Propagation, Electronic Control, and Networking (PROCONET) of Universidad de las Fuerzas Armadas ESPE. This work has been developed with the support of VLIR-UOS and the Belgian Development Cooperation (DGD) under the project EC2020SIN322A101. This work has been partially supported by the Spanish Ministry of Industry and Competitiveness under the grants DPI2015-67292-R and FEDER ECO 1823-2015.

\section{REFERENCES}

[1] Z. Zhang, H. Tang, and Q. Huang, "Risk Implemented Simultaneous Game-Theoretic Approach for Energy Trading in Residential Microgrids," Energy Procedia, vol. 158, pp. 6679-6686, Feb. 2019.

[2] P. P. Vergara, J. C. López, J. M. Rey, L. C. P. da Silva, and M. J. Rider, "Energy Management in Microgrids," in Microgrids Design and Implementation, Cham: Springer International Publishing, 2019, pp. 195-216.

[3] D. Espín-Sarzosa, R. Palma-Behnke, and O. Núñez-Mata, "Energy Management Systems for Microgrids: Main Existing Trends in Centralized Control Architectures," Energies, vol. 13, no. 3, p. 547, Jan. 2020

[4] S. Aznavi, P. Fajri, R. Sabzehgar, and A. Asrari, "Optimal management of residential energy storage systems in presence of intermittencies," Journal of Building Engineering, vol. 29, p. 101149 , May 2020.

[5] H. Afrakhte and P. Bayat, "A contingency based energy management strategy for multi-microgrids considering battery energy storage systems and electric vehicles," Journal of Energy Storage, vol. 27, Oct. 2019, pp. 101087, 2020.

[6] W. Liu, J. Zhan, and C. Y. Chung, "Transactions on Power Systems A Novel Transactive Energy Control Mechanism for Collaborative Networked Microgrids," IEEE Trans. Power Syst., vol. PP, no. c, p. 1, 2018.

[7] F. Khavari, A. Badri, and A. Zangeneh, "Electrical Power and Energy Systems Energy management in multi-microgrids considering point of common coupling constraint," Electr. Power Energy Syst., vol. 115, no. August 2019, p. 105465, 2020.

[8] N. Bazmohammadi, A. Tahsiri, and A. Anvari-moghaddam, "Electrical Power and Energy Systems A hierarchical energy management strategy for interconnected microgrids considering uncertainty," International Journal of Electrical Power \& Energy Systems, vol. 109, no. October 2018, pp. 597-608, 2019.

[9] X. Wu et al., "A Two-layer Distributed Cooperative Control Method for Islanded Networked Microgrid Systems," IEEE Trans. Smart Grid, vol. PP, no. c, p. 1, 2019.

[10] H. Gao, S. Xu, Y. Liu, L. Wang, Y. Xiang, and J. Liu, "Decentralized optimal operation model for cooperative microgrids considering renewable energy uncertainties," Applied Energy, vol. 262, no. October 2019, p. 114579, 2020.

[11] W. Zhang and Y. Xu, "Distributed Optimal Control for Multiple Microgrids in a Distribution Network," vol. 3053, no. c, 2018.

[12] D. L. Rodrigues, X. Ye, X. Xia, and B. Zhu, "Battery energy storage sizing optimisation for different ownership structures in a peer-to-peer energy sharing community the "Applied Energy, vol. 262, no. September 2019, p. 114498, 2020.

[13] S. E. Ahmadi and N. Rezaei, "Electrical Power and Energy Systems A new isolated renewable based multi microgrid optimal energy management system considering uncertainty and demand response," International Journal of Electrical Power \& Energy Systems, vol. 118, no. December 2019, p. 105760, 2020. 
[14] O. Van Cutsem, D. H. Dac, P. Boudou, and M. Kayal, "Electrical Power and Energy Systems Cooperative energy management of a community of smart-buildings: A Blockchain approach," Electr. Power Energy Syst., vol. 117, no. August 2019, p. 105643, 2020.

[15] K. Mahmud, M. S. H. Nizami, J. Ravishankar, M. J. Hossain, and P. Siano, "Multiple Home-to-Home Energy Transactions for Peak Load Shaving," IEEE Trans. Ind. Appl., vol. 56, no. 2, pp. 1074-1085, Mar. 2020 .

[16] N. Liu, J. Wang, L. Wang, and S. Member, "Hybrid Energy Sharing for Multiple Microgrids in an Integrated Heat-Electricity Energy System,” IEEE Trans. Sustain. Energy, vol. PP, no. c, p. 1, 2018.

[17] M. B. Roberts, A. Bruce, and I. Macgill, "Opportunities and barriers for photovoltaics on multi-unit residential buildings: Reviewing the Australian experience," Renewable and Sustainable Energy Reviews, vol. 104, no. August 2017, pp. 95-110, 2019.

[18] H. Wang and J. Huang, "Incentivizing Energy Trading for Interconnected Microgrids," vol. 3053, no. c, pp. 1-11, 2016.

[19] B. P. Baez-gonzalez, E. Rodriguez-diaz, J. C. Vasquez, and J. M. Guerrero, "Peer-to-Peer Energy Market for Community Microgrids," IEEE Electrif. Mag., vol. 6, no. december 2018, pp. 102-107, 2020.

[20] G. Van Leeuwen, T. Alskaif, M. Gibescu, and W. Van Sark, "An integrated blockchain-based energy management platform with bilateral trading for microgrid communities," Applied Energy, vol. 263, no. October 2019, p. 114613, 2020.

[21] L. K. Gan, A. Hussain, S. Member, D. A. Howey, H. Kim, and S Member, "Limitations in Energy Management Systems: A Case Study for Resilient Interconnected Microgrids," IEEE Trans. Smart Grid, vol. PP, no. c, p. 1, 2018.

[22] M. A. Hossain, H. R. Pota, S. Squartini, F. Zaman, and K. M Muttaqi, "Energy management of community microgrids considering degradation cost of battery," Journal of Energy Storage, vol. 22, pp. 257-269, Apr. 2019.
[23] D. Arcos-Aviles, J. Pascual, L. Marroyo, P. Sanchis, and F. Guinjoan, "Fuzzy Logic-Based Energy Management System Design for Residential Grid-Connected Microgrids," IEEE Trans. Smart Grid, vol. 9, no. 2, pp. 530-543, Mar. 2018.

[24] D. Arcos-Aviles, J. Pascual, F. Guinjoan, L. Marroyo, P. Sanchis, and M. P. Marietta, "Low complexity energy management strategy for grid profile smoothing of a residential grid-connected microgrid using generation and demand forecasting," Applied Energy, vol. 205, pp. 69-84, Nov. 2017.

[25] D. Arcos-Aviles et al., "A Review of Fuzzy-Based Residential GridConnected Microgrid Energy Management Strategies for Grid Power Profile Smoothing," in Energy Sustainability in Built and Urban Environments, E. Motoasca, A. Kumar Agarwal, and H. Breesch, Eds. Singapore: Springer Nature Singapore Pte Ltd, 2019, pp. 165-199

[26] J. Marcos, I. de la Parra, M. García, and L. Marroyo, "Control Strategies to Smooth Short-Term Power Fluctuations in Large Photovoltaic Plants Using Battery Storage Systems," Energies, vol. 7, no. 10 , pp. 6593-6619, Oct. 2014.

[27] D. A. Aviles, F. Guinjoan, J. Barricarte, L. Marroyo, P. Sanchis, and H. Valderrama, "Battery management fuzzy control for a grid- tied microgrid with renewable generation," in Proc. IECON 2012 - 38th Annual Conference on IEEE Industrial Electronics Society, Montreal, QC, Canada, Oct. 2012, pp. 5607-5612.

[28] J. Pascual, J. Barricarte, P. Sanchis, and L. Marroyo, "Energy management strategy for a renewable-based residential microgrid with generation and demand forecasting," Applied Energy, vol. 158, pp. 12-25, Nov. 2015.

[29] J. Pascual, P. Sanchis, and L. Marroyo, "Implementation and Control of a Residential Electrothermal Microgrid Based on Renewable Energies, a Hybrid Storage System and Demand Side Management," Energies, vol. 7, no. 1, pp. 210-237, Jan. 2014 